\title{
Study on Cellulase Gene Expressed in Pichia pastoris and Analyses of Its Biochemical Characters
}

\author{
Min Lu1, Juan Chang1, Ping Wang1, Qingqiang Yin ${ }^{*}$, Xiaowei Dang², Tianzeng Gao ${ }^{3}$, Fushan Lu ${ }^{4}$ \\ ${ }^{1}$ College of Animal Science and Veterinary Medicine, Henan Agricultural University, Zhengzhou, China \\ ${ }^{2}$ Henan Delin Biological Product Co. Ltd., Xinxiang, China \\ ${ }^{3}$ Henan Guangan Biotechnology Co., Ltd., Zhengzhou, China \\ ${ }^{4}$ Henan Engineering and Technology Research Center of Feed Microbes, Zhoukou, China \\ Email: *qqy1964@126.com
}

How to cite this paper: Lu, M., Chang, J., Wang, P., Yin, Q.Q., Dang, X.W., Gao, T.Z. and Lu, F.S. (2018) Study on Cellulase Gene Expressed in Pichia pastoris and Analyses of Its Biochemical Characters. Journal of Materials Science and Chemical Engineering, 6, 43-52.

https://doi.org/10.4236/msce.2018.67006

Received: February 24, 2018

Accepted: July 1, 2018

Published: July 4, 2018

\begin{abstract}
Objectives: In order to increase cellulose degradation, cellulase was expressed in this study. Literature Review: Cellulose is the most abundant organic carbon source on Earth; its enzymatic hydrolysis will be very useful for bioenergy production and resource recycling. Methods: Cellobiohydrlase I (CBH I) gene was amplified from genomic DNA of Trichoderma koningii and inserted into pGAPZ $\alpha$ A plasmid to construct the vector of pGAPZ $\alpha \mathrm{A}-\mathrm{CBH}$ I. It was linearized and transformed into Pichia pastoris by electroporation. The recombinant Pichia pastoris was selected and incubated with YPD medium for cellulase secretion. Results: The result showed that CMCase and avicelase activity in the supernatant was $1.1798 \mathrm{U} / \mathrm{mL}$ and $0.1276 \mathrm{U} / \mathrm{mL}$, the molecular weight of the expressed protein was $53 \mathrm{kDa}$ determined with SDS-PAGE analyses, and the optimal temperature and $\mathrm{pH}$ of the expressed cellulase were $45^{\circ} \mathrm{C}$ $50^{\circ} \mathrm{C}$ and 4.5 - 5.0, respectively. Conclusion: Cellulase gene from T. koningii has been successfully cloned and expressed in Pichia pastoris.
\end{abstract}

\section{Keywords}

Cellulase Gene, Cloning and Expression, Biochemical Characters, Pichia pastoris

\section{Introduction}

Cellulose, the most abundant organic carbon source, is one kind of recycled biological resource that accounts $1 / 3-1 / 2$ of the dry plant weight on earth. Crop straws are the main resources of cellulose. Due to their low applications, a lot of 
them are buried as fertilizer, decayed in the fields or burned on the spot, which cause waste and pollution. If these native resources can be effectively used, it will be conducive to solve environmental pollution, feed shortage and energy crisis. Cellulose is composed of $\beta$-1,4-linked glucose units and contains both highly crystalline and amorphous (non-crystalline) regions [1]. A set of enzymes are needed for the complete degradation of cellulose [2]. Depending on their different actions, cellulase family consists of three types such as endo- $\beta$-1,4-glucanase, exo- $\beta$-1,4-glucanase (cellobiohydrolase) and $\beta$-glucosidase [3]. Cellulase is produced by a broad range of organisms including fungi, bacteria, plants and insects. Among these organisms, fungal cellulase has been widely studied.

Although cellulase is widely applied, the large-scale industrial production of cellulase has been restricted by low enzyme activity, high cost and many other factors. In order to improve cellulaseproduction, genetic engineering technologyhas been paid more and more attention. The first cellulase gene was cloned in 1982 [4], and then most of cellulase genes have been expressed in E. coli, S. cerevisiae and Pichia pastoris (P. pastoris) [5] [6] [7], but the expressed cellulase activity was low. It is needed to select the different vector and host to produce high levels of cellulase for commercial use.Cellobiohydrlase I (CBH I) is believed to be the most efficient enzyme which can release cellobiose as the main product from highly crystalline cellulose [8]. Pichia pastoris has been developed as a widely used host organism for recombinant protein production [9]. It can secrete low levels of its own proteins and high levels of the expressed proteins [10]. In order to increase cellulase production and application, the $C B H$ I gene from a high cellulase-producing strain of Trichoderma koningii was expressed in Pichia pastoris in this study to provide the base for cellulose degradation and application.

\section{Materials and Methods}

\subsection{Microorganisms, Plasmid and Incubating Media}

Trichoderma koningii ( T. koningii, CGMCC3.0168) was incubated in PDA medium $(0.6 \%$ starch soluble, $0.5 \%$ trypton, $0.2 \%$ yeast extract, $2 \%$ glucose, $0.2 \%$ $\left.\mathrm{K}_{2} \mathrm{HPO} 4,0.03 \% \mathrm{MgSO}_{4} \cdot 7 \mathrm{H}_{2} \mathrm{O}\right)$. PMD19-T plasmid was purchased from TaKaRa Company, P. pastoris (X-33) and pGAPZaAplasmid were purchased from Invitrogen Company. Escherichia coli (DH5 $\alpha$ ) was incubated in LB medium (1\% trypton, $0.5 \%$ yeast extract, and $1 \% \mathrm{NaCl}) . P$. pastoris was incubated in YPD medium ( $1 \%$ yeast extract, $2 \%$ peptone, $2 \%$ glucose) or YPDS medium (1\% yeast extract, $2 \%$ peptone, $2 \%$ glucose, $1 \mathrm{~mol} / \mathrm{L}$ sorbitol).

\subsection{Genomic DNA and PCR Amplification of CBH I Gene}

The genomic DNA of T. koningii was prepared according to the former protocol [11]. CBH I gene was amplified with a pair of up-stream and down-stream specific oligonucleotide primers ( $\mathrm{P} 1$ and $\mathrm{P} 2$ ) designed with $\mathrm{CBH}$ I gene sequences from GeneBank at the National Center for Biotechnology Information (NCBI). 
To facilitate subsequent cloning of the PCR-derived fragments, $K p n I$ and $X b a I$ restriction sites were added to the 5'-ends of $\mathrm{P} 1$ and $\mathrm{P} 2$ primers, respectively.

P1: 5'-GCG GGTACC CAGTCGGCCTGCACTCTCC-3'

Kpn I.

P2: 5'-CGC TCTAGA CAGGCACTGAGAGTAGTAAGGGTTC-3'

Xba I.

Amplification of the DNA fragments encoding CBH I gene was performed by using polymerase chain reaction (PCR). PCR reactions contained $25 \mu \mathrm{L} 2 \times \mathrm{Pfu}$ PCR mastermix (Promega), 18.5 $\mu \mathrm{L}$ nuclease-free water, $2.5 \mu \mathrm{L}$ DNA template, $2.0 \mu \mathrm{L}$ primers. Reaction conditions for PCR amplification were 25 cycles with $94^{\circ} \mathrm{C}$ for $0.5 \mathrm{~min}, 55^{\circ} \mathrm{C}$ for $0.5 \mathrm{~min}$, and $72^{\circ} \mathrm{C}$ for $2.5 \mathrm{~min}$, followed by a final extension at $72^{\circ} \mathrm{C}$ for $8 \mathrm{~min}$. PCR products were separated by electrophoresis with $1 \%$ agarose and purified by High Pure PCR Product Purification Kit (Aidlab). $\mathrm{CBH}$ I gene fragment was connected with PMD19-T, and then introduced into competent cells of DH $5 \alpha$ (Tiangen Biotech). The recombinants were screened by blue white plaque test [12]. After extraction of the recombinant vectors, double endonuclease digestion was used to identify them.

\subsection{Construction of Recombinant Expression Vector of pGAPZ $\alpha A-C B H$ I}

CBH I gene was obtained from the vector of PMD19-T-CBH I through KpnI and $X b a I$ double endonuclease digestion, and connected with pGAPZ $\alpha$ Aplasmid by ligase which was also digested by $K p n \mathrm{I}$ and $X b a \mathrm{I}$. The recombinant shuffle vector was introduced into competent cells of DH5 $\alpha$ by chemical method [12]. Positive cloning strains were selected by low salt LB medium with Zeocin and identified by double $K p n I$ and $X b a I$ digestion.

\subsection{Transformation of $P$. pastoris and Screening of Recombinant Colonies}

Transformation of the recombinant expression vector into $P$. pastoris was performed by electroporation according to the instruction manual for the EasySelect ${ }^{\mathrm{TM}}$ Pichia expression system (Invitrogen). Before transformation, the expression cassette pGAPZ $\alpha \mathrm{A}-C B H \mathrm{I}$ was linearized with $B \ln \mathrm{I}$ and purified with agarose.

The competent cell of $P$. pastoris was prepared as follow: $P$. pastoris was incubated in $100 \mathrm{~mL}$ YPD medium at $30^{\circ} \mathrm{C}$ until cells grew to an optical density of $1.1-1.3$ at $600 \mathrm{~nm}$, then the cells were harvested and kept on ice. The cells were centrifuged at 3000 rounds per $\min (\mathrm{RPM})$ for $5 \mathrm{~min}$ at $4^{\circ} \mathrm{C}$, washed twice with $100 \mathrm{~mL}$ ice-cold $\mathrm{ddH}_{2} \mathrm{O}$, and washed once with $20 \mathrm{~mL}$ ice-cold $1 \mathrm{~mol} / \mathrm{L}$ sorbitol. The cells were finally re-suspended in $0.5 \mathrm{~mL}$ of $1 \mathrm{~mol} / \mathrm{L}$ sorbitol. Eighty $\mu \mathrm{L}$ yeast competent cells were mixed with $5-10 \mu \mathrm{g}$ vector and transferred into an ice-cold $0.2 \mathrm{~cm}$ electroporation cuvette. A single pulse of $1.6 \mathrm{kV}$ was applied with a capacitance of $25 \mu \mathrm{F}$ and resistance of $400 \Omega$. After electroporation, $1 \mathrm{~mL}$ of ice-cold $1 \mathrm{~mol} / \mathrm{L}$ sorbitol solution was immediately added to the cuvettes, and 
the cuvette contents were transferred to $10 \mathrm{~mL}$ tube. After incubation at $30^{\circ} \mathrm{C}$ for $1 \mathrm{~h}$ without shaking, cells were spread on YPDS agar plates containing 100 $\mu \mathrm{g} / \mathrm{mL}$ Zeocin (Invitrogen) and incubated at $30^{\circ} \mathrm{C}$ for $2 \mathrm{~d}$. YPDS agar plates without zeocin were used as control.

To confirm integration of CBH I gene in the $P$. pastoris genome, two primers (P3 and P4) were designed based on CBH I sequence. The length of PCR products amplified by these two primers should be $1013 \mathrm{bp}$.

P3: 5'-GCTTCGTCACGCAATCTG-3'.

P4: 5'-GGTCTCGTTTGTCGGGTAGG-3'.

\subsection{Cellulase Activity Determination of the Transformed P. pastoris}

The media used for incubating the transformed $P$. pastoris were YPD medium and YPD medium containing $0.2 \%$ Tween 80 . The incubation was carried out in $250 \mathrm{~mL}$ Erlenmeyer flasks containing $70 \mathrm{~mL}$ medium in a rotary shaker of 180 $\mathrm{RPM}$ at $30^{\circ} \mathrm{C}$. Incubation lasted for $7 \mathrm{~d}$, during which $2 \mathrm{~mL}$ incubation was sampled each day. The supernatant was prepared by centrifugation at 12,000 RPM for $5 \mathrm{~min}$. Carboxymethyl cellulose enzyme (CMCase) activity and avicelase activity in supernatant was determined with a colorimetric method by using a 3,5-dinitrosalicylic acid (DNS) assay with CMC and avicel as the substrates. 0.5\% $\mathrm{CMC}$ or avicel substrate was prepared by $50 \mathrm{mmol} / \mathrm{L}$ sodium citrate buffer at $\mathrm{pH}$ 4.8. The reaction mixture containing $0.5 \mathrm{~mL}$ of enzyme solution, $1.5 \mathrm{~mL}$ of $0.5 \% \mathrm{CMC}$ or avicel was incubated at $50^{\circ} \mathrm{C}$ for 30 or $60 \mathrm{~min}$. The reaction was terminated by adding $1 \mathrm{~mL}$ DNS reagent and boiling at $100^{\circ} \mathrm{C}$ for $5 \mathrm{~min}$. The absorption of the reaction mixture was measured at $540 \mathrm{~nm}$ by using a UV spectrophotometer [13]. One unit (U) of enzyme activity is defined as the amount of enzyme that produces $1 \mu \mathrm{mol}$ of $\mathrm{D}$-glucose in one minute under the assay conditions.

\subsection{Determination of Cellulase Biochemical Characters}

Cellulase thermostability was estimated according to the following protocol: 2 $\mathrm{ml}$ sample was added into the pre-warmed $(30 \mathrm{~min}) 10 \mathrm{ml}$ test tubes with lid. The duplicates were 3 for each temperature points. The temperature levels were: $30^{\circ} \mathrm{C}, 35^{\circ} \mathrm{C}, 40^{\circ} \mathrm{C}, 45^{\circ} \mathrm{C}, 50^{\circ} \mathrm{C}, 55^{\circ} \mathrm{C}, 60^{\circ} \mathrm{C}, 70^{\circ} \mathrm{C}, 80^{\circ} \mathrm{C}$. The reaction was stopped by putting the tubes into ice immediately after $15 \mathrm{~min}$ reaction. The residual cellulase activity was estimated with the above protocol.

The optimal $\mathrm{pH}$ was determined with the following 8 levels of $\mathrm{pH}$ buffers: 0.2 $\mathrm{M}$ sodium citrate-citric acid ( $\mathrm{pH} 3.0,3.5,4.0,4.5,5.0,5.5,6.0$ and 7.0), and the residual cellulase activity was estimated with the above protocol.

\subsection{Sodium Dodecyl Sulfate (SDS)-Polyacrylamide Gel Electrophoresis (PAGE) Analysis}

Analytical SDS-PAGE was performed with $12 \%$ polyacrylamide gel. The gels were stained with coomassie brilliant blue R-250 (Sambrook and Russell 2001). 
Supernatant sample was performed by boiling at $100^{\circ} \mathrm{C}$ for $5 \mathrm{~min}$ with equal volume of $5 \times$ SDS-PAGE loading buffer (250 mM Tris- $\mathrm{HCl}, 10 \%$ SDS (w/v), $0.5 \%$ BPB (w/v), 50\% Glycerine (v/v), $5 \% \beta$-mercaptoethanol (w/v)), and centrifuged at 10,000 RPM for $3 \mathrm{~min}$. The electrophoresis was set with $50 \mathrm{~V}$ for the first 30 min and then kept at $100 \mathrm{~V}$. Incubation supernatant of native $P$. pastoris was used as control.

\subsection{Statistical Analysis}

The data were analyzed using the ANOVA procedures of Statistical Analysis Systems Institute, 2004. Duncan's multiple range test was used to evaluate treatment means. The results were considered statistically significance at $\mathrm{P}<$ 0.05 .

\section{Results and Discussion}

\subsection{CBH I Geneexpression in P. pastoris and Enzyme Activity Determination}

The CBH I gene was amplified from genomic DNA of $T$. koningii and ligated with PMD19-T plasmid to construct PMD19-T-CBHI vector, which was confirmed by double endonuclease digestion. The CBH I gene (1626 bp) was sequenced and submitted to the NCBI data base under accession of No.JX103160. Blast analysis indicated that it had a high homology of $99.63 \%$ with CBH I gene of Trichoderma viride (No. FJ871063.1). Comparison of the cloned sequence with the mRNA sequence in Genebank showed that this gene contained two introns of $66 \mathrm{bp}$ and $69 \mathrm{bp}$ in length. A protein of 497 amino acids should be encoded and the molecular weight was about $52.29 \mathrm{KDa}$.

CBH I gene fragment (1626 bp) from PMD19-T-CBH I was ligated with pGAPZ $\alpha$ A. The recombinant pGAPZ $\alpha$ A-CBH I was confirmed by double endonuclease digestion (Figure 1). Integration of $\mathrm{CBH}$ I gene into $P$. pastoris genome was confirmed with PCR by using gene-specific primers of P3 and P4 (Figure 2). From PCR result, it was shown that the positive clones had a bright band at about $1000 \mathrm{bp}$ point, and no band for the native $P$. pastoris. Sequencing result of this PCR product indicated that $\mathrm{CBH}$ I gene was integrated into P. pastoris successfully.

Cellulase protein from the incubating supernatant of the transformed $P$. pastoris was analyzed with SDS-PAGE. There was a band at $52.29 \mathrm{KDa}$ for the transformed P. pastoris and no band for the native P. pastoris (Figure 3). This result was in agreement with the calculated molecular weight of $52.29 \mathrm{kDa}$ based on the obtained amino acid sequence information. Figure 4 and Figure 5 indicated that cellulase activity in the incubation supernatant of transformed $P$. pastoris containing $0.2 \%$ Tween 80 was higher than that without Tween 80 . Avilase activity reached the peak $(0.1276 \mathrm{U} / \mathrm{mL})$ at the third day incubation, and CMCase activity reached the peak $(1.1798 \mathrm{U} / \mathrm{mL})$ at the fourth day incubation. Both of them would decrease with incubation prolonging. 


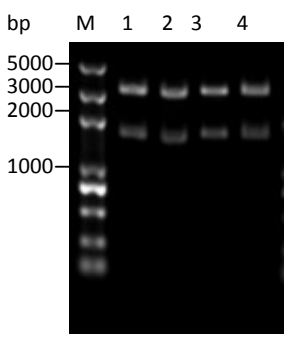

Figure 1. The double endonuclease digestion results of pGAPZaA-CBH I. M: Trans2K Plus DNA Marker; Lane 1 - 4: recombinant pGAPZ $\alpha A-C B H ~ I$ digested by $K p n I$ and $X b a I$.

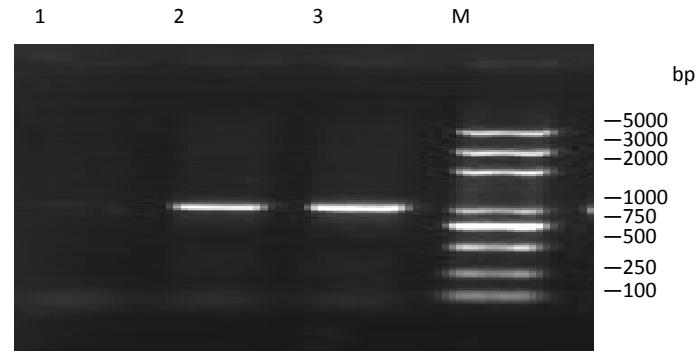

Figure 2. The PCR results of genomic DNA of $P$. pastoris. M: Trans2K Plus DNA Marker; Lane 1: PCR identification of native $P$. pastoris, Lane 2 - 3: PCR identification of recombinant $P$. pastoris.

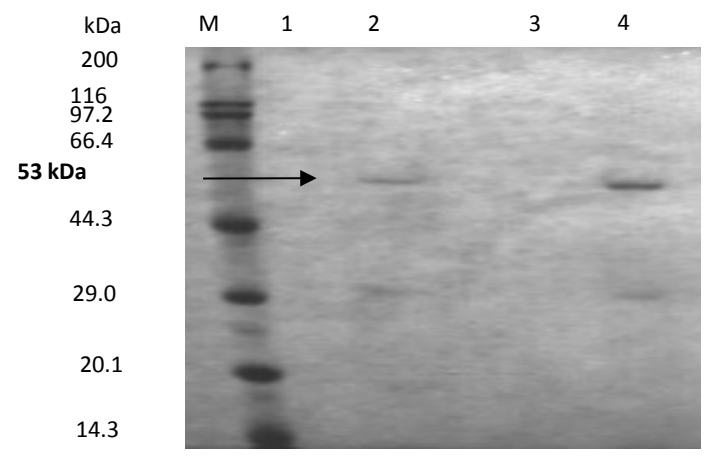

Figure 3. The SDS-PAGE of incubation supernatant. M: Protein molecular weight of marker; Lane 1 and 3: incubation supernatant of native $P$. pastoris; Lane 2 and 4: incubation supernatant of recombinant $P$. pastoris.

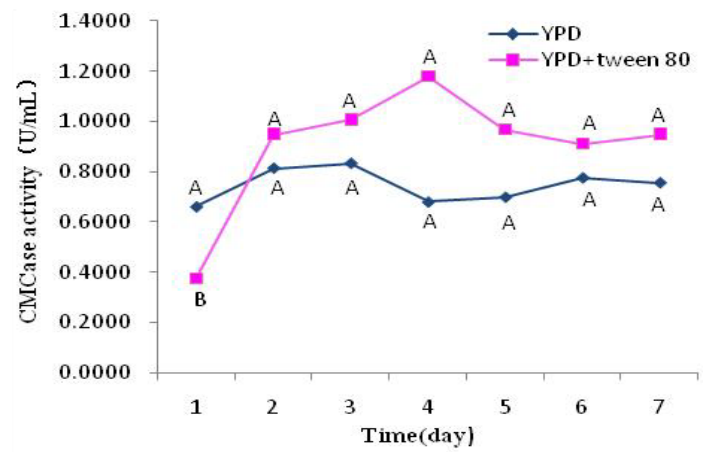

Figure 4. The CMCase activity of recombinant $P$. pastoris. Note: The different letters mean significant difference $(\mathrm{P}<0.05)$; while the same letters mean insignificant difference $(\mathrm{P}>0.05)$. 


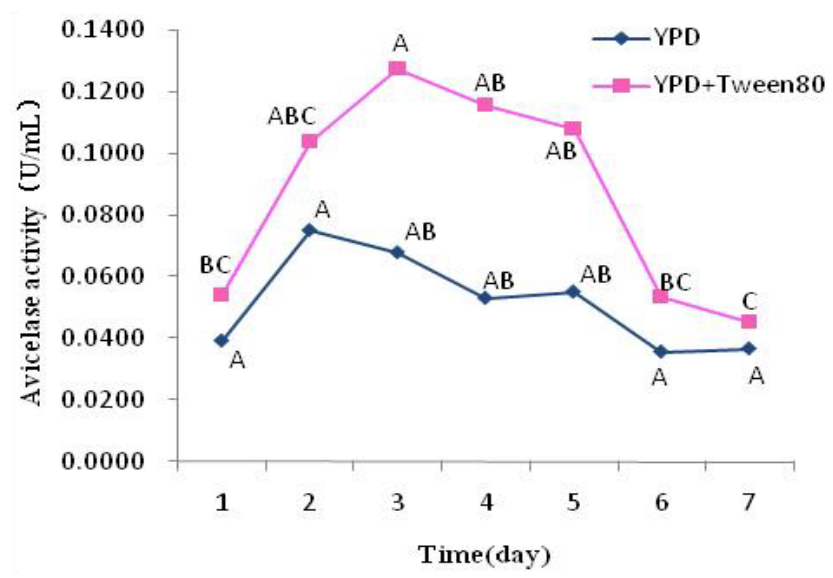

Figure 5. The avicelaseactivity of recombinant $P$. pastoris. Note: The different letters mean significant difference $(\mathrm{P}<0.05)$; while the same letters mean insignificant difference $(P>0.05)$.

CBH I gene has been previously expressed in E. coli and S. cerevisiae [5] [6]; however, the expressed cellulase activity is not very high due to the following two problems. The first one is that the enzyme is not secreted and remained as inclusion bodies in cytoplasm when it is expressed in E. coli [5]. The second one is that cellulase secreted by $S$. cerevisiaeis hyper-glycosylated resulting in reduced substrate-binding capacity and catalytic activity [6]. Even though CBH II gene has been expressed in P. pastoris [7], CBH I gene has not been studied and expressed in P. pastoris. P. pastoris represented an appropriate host for the heterologous expression of functional fungal endoglucanase [14], but the cellulase activity of recombinant yeast was only $0.0670 \mathrm{U} / \mathrm{mL}$ [15], which was lower than that in this study $(1.1798 \mathrm{U} / \mathrm{mL}$ CMCase activity and $0.1276 \mathrm{U} / \mathrm{mL}$ avicelase activity).

Tween 80 is a surface active agent.It can reduce the surface tension between the microbial cells and medium surface, stimulate the production of a variety of extracellular enzymes, impact cell membrane permeability, and promote nutrients entering cells and metabolites excreted out of cells [16]. The higher cellulase production with Tween 80 addition in this study proves that Tween 80 is able to stimulate cellulase excretion.

\subsection{The Optimum Temperature and pH of Cellulose}

Figure 6 showed that CMCase and avicelase activity was higher when temperature was below $50^{\circ} \mathrm{C}$, which decreased quickly as temperature was above $60^{\circ} \mathrm{C}$. Figure 7 indicated that the optimal pH was 4.0 - 6.0 for CMCase and 5.0 - 5.5 for avicelase. The result was consistent with the former research [17]. The relative cellulase activity decreased significantly when temperature was above $60^{\circ} \mathrm{C}$ due to enzyme protein structure changing at high temperature. At $\mathrm{pH}$ ranges of 3.0 3.5 and $6.0-7.0$, the relative cellulase activity was very low due to the protein structure of cellulase changed under the strong alkali or acid conditions to make cellulase lose its activity. 


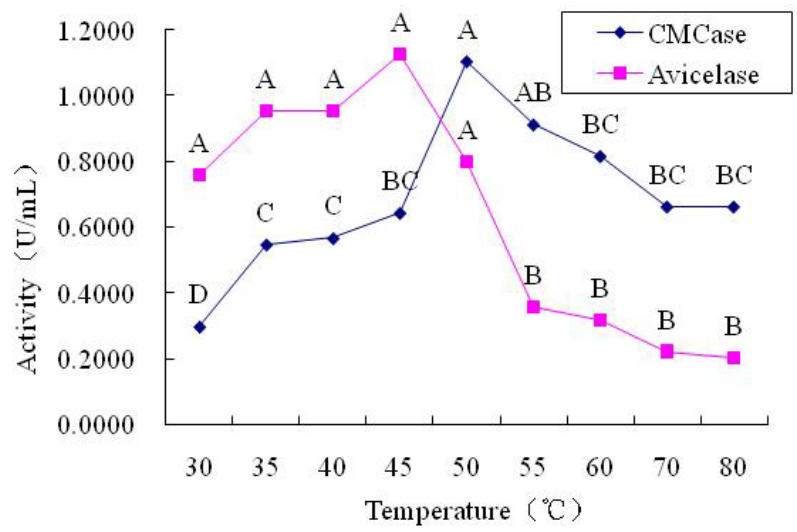

Figure 6. Effect of temperature on cellulase activity of recombinant Pichia pastoris. Note: The different letters mean significant difference $(P<0.05)$; while the same letters mean insignificant difference $(\mathrm{P}>0.05)$.

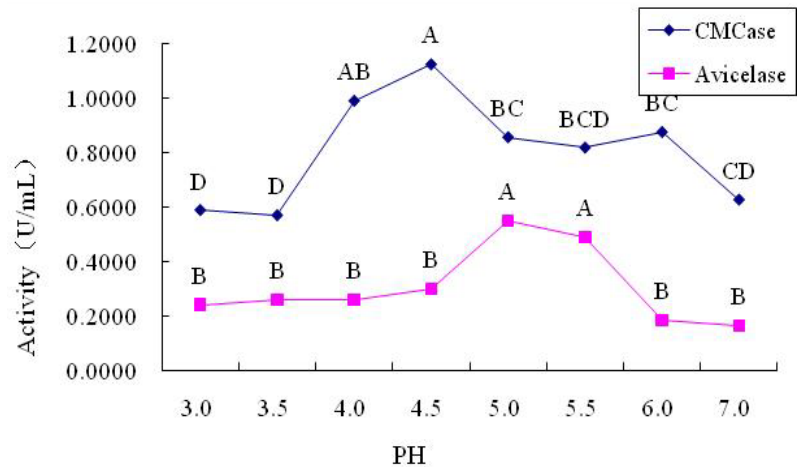

Figure 7. Effect of $\mathrm{pH}$ on cellulase activity of recombinant Pichia pastoris. Note: The different letters mean significant difference $(\mathrm{P}<0.05)$; while the same letters mean insignificant difference $(\mathrm{P}>0.05)$.

\section{Conclusion}

The CBH I gene from T. koningii has been successfully cloned and expressed in $P$. pastoris, and cellulase biochemical characters were also analyzed. Otherwise, the complete degradation of cellulose is a result of the synergistic effect of cellulase family, so co-expressing a series of cellulase genes in a host would have great significance for cellulose degradation.

\section{Acknowledgements}

This work was financially supported by China Spark Program (2015GA750012), Henan Key Scientific and Technological Project (171100110500), Henan Production-Study-Research Cooperation Program (162107000069).

\section{References}

[1] Zhang, Y.H.P. and Lynd, L.R. (2004) Toward an Aggregated Understanding of Enzymatic Hydrolysis of Cellulose: Noncomplexed Cellulase Systems. Biotechnology and Bioengineering, 88, 797-824. https://doi.org/10.1002/bit.20282

[2] Bhat, M.K. and Bhat, S. (1997) Cellulose Degrading Enzymes and Their Potential 
Industrial Applications. Biotechnology Advances, 15, 583-620. https://doi.org/10.1016/S0734-9750(97)00006-2

[3] Beguin, P. and Lemaire, M. (1996) The Cellulosome: An Exocellular, Multi-Protein Complex Specialized in Cellulose Degradation. Critical Reviews in Biochemistry and Molecular Biology, 31, 201-236. https://doi.org/10.3109/10409239609106584

[4] Whittle, D.J., Kilburn, D.G., Warren, R.A.J. and Miller, J.R.C. (1982) Molecular Cloning of a Cellulomonas fimi Cellulase Gene in Escherichia coli: Recombinant DNA; Plasmid pBR322; Immunoassay. Gene, 17, 139-145. https://doi.org/10.1016/0378-1119(82)90066-X

[5] Laymon, R.A., Adney, W.S., Mohagheghi, A., Himmel, M.E. and Thomas, S.R. (1996) Cloning and Expression of Full-Length Trichoderma reesei Cellobiohydrolase I cDNA in Escherichia coli. Applied Biochemistry and Biotechnology, 57/58, 389-397. https://doi.org/10.1007/BF02941718

[6] Penttila, M., Andre, L., Lehtovaara, P., Bailey, M., Teeri, T.T. and Knowles, J. (1988) Efficient Secretion of Two Cellobiohydrolases by Saccharomyces cerevisiae. Gene, 63, 103-112. https://doi.org/10.1016/0378-1119(88)90549-5

[7] Zahri, S., Zamani, M.R., Motallebi, M. and Sadeghi, M. (2005) Cloning and Characterization of $\mathrm{CBH}$ II Gene from Trichoderma parceramosum and Its Expression in Pichia pastoris. Iranian Journal of Biotechnology, 3, 204-215.

[8] Koivula, A., Ruohonen, L., Wohlfahrt, G., Reinikainen, T., Teeri, T.T., Piens, K., Claeyssens, M., Weber, B., Vasella, A., Becker, D., Sinnott, M.L., Zou, J., Kleywegt, G., Szardenings, M., Stahlberg, J. and Jones, T.A. (2002) The Active Site of the Cellobiohydrolase Cel6A from Trichoderma reesei: The Roles of the Aspartic Acids D221 and D175. Journal of the American Chemical Society, 124, 10015-10024. https://doi.org/10.1021/ja012659q

[9] Cereghino, J.L. and Cregg, J.M. (2000) Heterologous Protein Expression in the Methylotrophic Yeast Pichia pastoris. FEMS MicrobiologyReviews, 24, 45-66. https://doi.org/10.1111/j.1574-6976.2000.tb00532.x

[10] Romanos, M.A., Scorer, C.A. and Clare, J.J. (1992) Foreign Gene Expression in Yeast: A Review. Yeast, 8, 423-428. https://doi.org/10.1002/yea.320080602

[11] Zhang, X.H., Guo, C.H., Jiang, X.X. and Luo, H. (2007) Studies on Extraction of Genomic DNA from Trichoderma koningii. Biotechnological Bulletin, 5, 128-130.

[12] Sambrook, J. and Russell, D.W. (2001) Molecular Cloning: A Laboratory Manual. 3rd Edition, Cold Spring Harbor.

[13] Coleman, D.J., Studler, M.J. and Naleway, J.J. (2007) A Long-Wavelength Fluorescent Substrate for Continuous Fluorometric Determination of Cellulase Activity: Resorufin- $\beta$-D-Cellobioside. Analytical Biochemistry, 371, 146-153. https://doi.org/10.1016/j.ab.2007.08.027

[14] Ding, S.J., Gea, W. and Buswell, J.A. (2002) Secretion, Purification and Characterization of a Recombinant Volvariella volvacea Endoglucanase Expressed in the Yeast Pichia pastoris. Enzyme and Microbial Technology, 31, 621-626. https://doi.org/10.1016/S0141-0229(02)00168-0

[15] Ding, X.L., Wang, T.H., Zhang, G.T. and Lu, Y. (2005) Study of the Expressions of Cellulase from Trichoderma reesei in Saccharomyces cerevisiae. Liquor-Making Science and Technology, 9, 28-35.

[16] Zhuang, X.L., Zhang, H.X., Ma, G.R. and Kong, J. (2000) Effect of Tween80 on the Growth of Lactococcus lactis SM526 and Nisin Activity. Engineering Chemistry of Metallurgy, 4, 145-148. 
[17] Quay, D.H.X., Baker, F.D.A., Rabu, A., Said, M., Illias, R.M., Mahadi, N.M., Hassan, O. and Murad, A.M.A. (2011) Overexpression, Purification and Characterization of the Aspergillus niger Endoglucanase, EglA, in Pichia pastoris. African Journal of Biotechnology, 10, 2101-2111. 